\title{
Transformasi Yudhisthira Mahabarata dalam Tradisi Pedalangan
}

\author{
Aris Wahyudi ${ }^{1}$ \\ Jurusan Pedalangan, Fakultas Seni Pertunjukan Institut Seni Indonesia Yogyakarta
}

\section{ABSTRAK}

Artikel ini menjelaskan konsep Yudistira dalam tradisi wayang sebagai kontinuitas Yudhistira dalam epos Mahabharata. Transformasi ini diikuti oleh konsep berkelanjutan yang dapatmengikuti dengan menggunakan konsep Jawa, asma kinarya japa. Dengan demikian dapat disimpulkan bahwa konsep Yudistira dalam tradisi pedalangan adalah sistem transformasi dilihat dari mitologi ritual. Meskipun ceritanya diadopsi dari India Mahabharata, namun Wayang Purwa menggambarkan pola pikir asli Jawa. Wayang Purwa telah diwariskan dari generasi ke generasi, namun telah mampu mempertahankan konsep aslinya.

Kata kunci: Yudistira, mahabarata, wayang

\section{ABSTRACT}

Hermeneutic Cirkle of Yudhistira in Puppetry Tradition. This article explains Yudistira's concept in a wayang tradition as a continuity of Yudhishthira in Mahäbhärata epic. The transformation was followed by continuous concept that can be trailed by employing Javanese theory, such as asma kinarya japa theory. It can be concluded that the concept of Yudistira in the pedalangan tradition is a transformation system viewed from the ritual mythology. Although its story is adopted from Indian Mahabharata, but Wayang Purwa illustrates an original Javanese mindset. Wayang Purwa has been inherited through generations, yet it has been able to maintain its original concept.

Keyword: Yudistira, Mahabarata, wayang

\section{Pendahuluan}

Sebagian besar para peneliti wayang mempersamakan antara jagad wayang (tradisi pedalangan Jawa) dengan Mahabharata (tradisi sastra), sehingga dikatakan bahwa wayang berasal dari India (Brandon, 2003: 18-26). Hal demikian dapat dimaklumi karena nama-nama tokoh dalam pedalangan banyak memiliki kesamaan dengan tradisi Mahãbhãrata, salah satunya adalah Puntadewa atau Yudistira. Namun dalam kesamaan tersebut ternyata memiliki perbedaan yang sangat signifikan. Puntadewa dalam tradisi Mahãbhãrata lebih dikenal sebagai Yudhishthira (penulisan dengan ejaan Yuddhishthira untuk merujuk tradisi Mahäbhärata, demikian berlaku untuk penulisan selanjutnya). Ia adalah seorang ahli perang dan prajurit yang tangguh (Katz, 1989: 34). Sebagai seorang ahli perang tentunya ia memiliki sifat tega untuk membunuh lawan. Karakter demikian sangat berbeda dengan Puntadewa dalam tradisi pedalangan (selanjutnya ditulis Puntadewa) meskipun ia juga memiliki nama Yudistira (Yudhishthira). Puntadewa merupakan tokoh yang selalu berusaha menghindari perang
Baratayuda dengan melarang saudaranya ketika berkehendak meminta haknya atas negara Astina.

Sebagai raja, Puntadewa memiliki gelar Prabu Puntadewa, Prabu Yudhistira, Prabu Darma Kusuma, Prabu Darmaputra, Prabu Darmawangsa, Prabu Gunatalikrama, dan Sang Ajathasatru. Setiap nama memiliki arti tersendiri, yakni sebagai berikut: Puntadewa: narendra péranganing jawata (raja yang menjadi bagian dari dewa); Yudhistira: makuthaning prajurit (pemimpin perang yang tangguh); Darmakusuma: sekaring kautaman (menjadi buah bibir segala kebaikan); Darmaputra: kapundhut putra déning Hyang Darma (menjadi putra angkat Batara Darma); Darmawangsa: karana dènira jumeneng nata manut rèh préntahing kadang (karena ia menjadi raja hanya menuruti kehendak semua saudaranya); Gunatalikrama: naléndra bisa nalèni basa (seorang raja yang sangat pandai menjaga perasaan orang lain meskipun harus mengorbankan dirinya); Ajathasatru: tubu naréndra kang tan darbé mengsah (seorang raja yang tidak memiliki musuh atau menjauhkan diri dari rasa permusuhan) (Wignyosutarno, 1996: 110).

1 Alamat korespondensi: Prodi Pedalangan ISI Yogyakarta. Jalan Parangtritis Km. 6,5 Sewon, Yogyakarta. Telepon: (0274) 375380.E-mail: ariswayang@yahoo.com. 
Berdasarkan makna nama-nama tersebut di atas, pengertian kata yudistira ternyata bertolak belakang dengan karakter Puntadewa. Yudistira yang berarti prajurit yang tangguh. Sifat demikian ternyata sama sekali tidak dimiliki Puntadewa, bahkan sebaliknya. Meskipun demikian masih digunakannya nama Yudistira menunjukkan adanya kesetiaan tradisi pedalangan untuk mengikuti tradisi asalnya. Fenomena demikian menunjukkan bahwa banyak aspek yang melatarbelakangi transformasi Yuddhishthira. Yang menjadi persoalan adalah bagaimana cara tradisi pedalangan melakukan transformasi mitos Yudistira? Jawaban dari permasalahan ini akan diperoleh dengan mengkaji makna yang terkandung dalam diri tokoh Puntadewa, baik secara terminologi maupun mitologi..

Puntadewa dipandang sebagai sebuah teks. Dalam transformasi teks dapat dikenali tanggapan penciptanya atas teks yang didapatkanya terdahulu. Seorang dalang menerima teks dari pendahulunya, kemudian ia menanggapi dan menafsirkan menjadi sanggit dan bahkan lakon baru. Dalang tersebut dipandang sebagai pencipta, dan demikian berkelanjutan. Dengan demikian karena peranan peneliti adalah sebagai pembaca dan penafsir teks maka kedudukan peneliti dipandang sebagai sisi lain (di luar dalang) dan menjadi bagian dari mata rantai sejarah yang ikut berperan dalam proses perubahan atau penciptaan teks.

Makna tokoh Puntadewa tidak tersimpan dalam sebuah lakon yang tunggal, tetapi tersusun dari beberapa lakon yang terjalin dalam membentuk satu kesatuan mitos (Ahimsa Putra, 2001: 80-82). Dengan demikian transformasi Puntadewa dapat dilacak melalui intertekstualitas yaitu hubungan dan kesinambungan dalam mata rantai lakon-lakon yang berhubungan dengan Puntadewa (Wiryamartana, 1990: 10-11). Makna Puntadewa dapat dianalisis melalui konsep asma kinarya japa (setiap nama selalu memiliki makna/ sebagai mantra) dalam masyarakat Jawa (Wahyudi, 2001: 205). Asma di sini mengandung pengertian sebagai 'sebutan' (pengucapan). Asma dapat diidentikkan dengan penanda sebagai wadah dari sebuah konsep. Dengan demikian konsep asma kinarya japa seperti halnya konsep linguistik dapat digunakan untuk melacak dan menjelaskan makna serta sumber konsep-konsep lakon wayang berdasarkan istilah yang digunakan. Penggunaan konsep asma kinarya japa dalam melacak transformasi Puntadewa dengan cara menafsirkan makna dari nama (gelar) Puntadewa dan kemudian merunut makna tersebut dalam tradisi asalnya yang memiliki kesejajaran makna. Dari sini kita tafsirkan kembali mengenai aspek-aspek yang memungkinkan terjadinya penyimpangan serta mendudukkan semua permasalahan yang ada dalam konteks alam pikiran Jawa.

\section{Tipikal Puntadewa sebagai Identifikasi Batara Darma}

Yang dimaksud tokoh Puntadewa atau Yudistira dalam tradisi pedalangan pada dasarnya adalah tokoh Yuddhishthira dalam tradisi Mahãbhãrata. Namun demikian karakter Yudistira Jawa (Puntadewa) sangat jauh berbeda dengan karakter Yuddhisahthira dalam tradisi Mahãbhãrata. Hal demikian merupakan usaha untuk menegaskan kapasitas Puntadewa yang dijadikan perhatian, baik karakter maupun maknanya yang disesuaikan dengan selera, minat dan penilaian yang berkaitan dengan latar belakang sosial-budaya-religius masyarakat tradisi pedalangan melalui proses transformasi (Kuntara, 1990: 463). Penonjolan sifat Puntadewa dapat dilihat pada beberapa gelar Puntadewa sebagai identifikasi sifat Puntadewa. Perbedaan karakter tersebut menunjukkan bahwa di Jawa telah terjadi proses transformasi wiracarita Mahãbhãrata oleh tradisi pedalangan. Namun demikian jejak-jejak tradisi masa lampaunya masih dapat dilacak melalui penggunaan beberapa gelar Puntadewa.

Nama Puntadewa diartikan narendra péranganing jawata. Puntadewa adalah seorang raja yang menjadi bagian dari dewa dalam pengertian bahwa Puntadewa memiliki keterkaitan dengan dewa, apabila ditinjau dari sisi silsilah, karakter, tipikal, ataupun aspek psikisnya (kapasitas). Pengertian istilah puntadewa tampak untuk menunjukkan pandangan Jawa mengenai raja. Raja adalah penguasa tunggal dalam mikrokosmos. Ia sebagai pengemban tugas dan wakil Tuhan dalam mengatur jalannya roda pemerintahan di bumi. Melalui raja, rahmat Tuhan mengalir rata ke seluruh rakyat dan negara. Ia berhak murba dan masésa seperti halnya Tuhan yang Maha Kuasa atas segala sesuatu di alam makrokosmos sehingga rakyat patuh dan tunduk kepada sabda raja. Sabda 
raja tak ubahnya sabda Tuhan (Aris Wahyudi, 2001: 192). Kaitannya dengan nama gelar sebagai wadah dan makna sebagai isi, tampak bahwa dalam transformasi aspek Illahi di sini mengalami diskontinu dengan memunculkan wadah (gelar), tetapi kontinuitas dalam maknanya.

Darmakusuma: sekaring kautaman dalam pengertian bahwa Puntadewa memiliki sifat sangat baik. Ia dipandang sebagai sumber dan model seluruh kebajikan di bumi. Puntadewa memiliki rasa ikhlas dan penyerahan diri yang melebihi tokoh lain. Ketulusan rasa kasihsayangnya terhadap sesama ditegaskan oleh ketidaksediaannya untuk perang bahkan menyakiti hati orang pun selalu dihindari. Puntadewa rela memberikan haknya atas negara Hastina kepada Kurawa seperti yang ditunjukkan pada permintaannya kepada Kresna dalam Lakon Kresna Duta dan Lakon Salya Gugur. Penegasan konsep dharma sebagai sumber kebajikan dan kebenaran dilakukan dengan memberi gelar Darmakusuma untuk mendudukkan sifatnya sebagai sumber segala kebajikan, keikhlasan, dan kejujuran yang kesemuanya menyatu dalam dirinya. Karakter demikian sering ditunjukkan, di antaranya dalam Lakon Durna Gugur. Dikisahkan bahwa Puntadewa tidak bersedia berbohong kepada begawan Durna ketika ditanya tentang berita kematian Aswatama. Puntadewa menjawab dengan jujur bahwa yang mati adalah Hestitama, tetapi penyebutan kata hesti sangat pelan sehingga Durna tidak mendengar. Dengan demikian transformasi tipikal aspek Darma mengalami kontinuitas dan sekaligus mengalami diskontinu ketika diwujudkan menjadi gelar-gelar Puntadewa.

Darmaputra: kapundhut putra déning Hyang Darma dalam pengertian bahwa diambil sebagai putra Batara Darma. Dalam tradisi Mahäbhãrata, dharma dipandang sebagai "hukum" atau "tata tertib dunia"; juga sebagai "sifat kebajikan", "kewajiban", "kebenaran" yang berkaitan dengan "niat baik" atas perhatiannya yang sangat besar terhadap dunia. Dewa Dharma dipandang sebagai penguasa hukum, dewa kebajikan, dewa kebenaran. Yuddhishthira dipandang sebagai putra dan sekaligus inkarnasi Dewa Dharma sehingga ia disebut Dharmaraja dan memiliki sifat bagaikan seorang brahmana (Katz, 1989: 30-34). Sifat Puntadewa tersebut mempertegas pandangan tradisi pedalangan terhadap kapasitas darma sebagai kebalikan dari kapasitas ksatria (Katz, 1989: 175). Bagi seorang kesatria, istri adalah harga diri. Negara adalah sadumuk bathuksanyari bumi yang harus dipertahankan sampai titik darah penghabisan.

Gelar Darmaputra merupakan bentuk kontinuitas konsep Yuddhishthira tradisi Mahãbhãrata. Yuddhishthira adalah putra dan sekaligus bagian dari Dharma (Hopkins, 1986: 62). Gelar Yuddhishthira adalah Dharmarãja. Ia adalah suami Laksmi dalam kapasitasnya sebagai Sri (kemakmuran) (Hopkins, 1986: 115). Kapasitas ini masih diikuti oleh tradisi pedalangan. Dewi Drupadi adalah inkarnasi Dewi Sri. Pemahaman Dewi Sri dalam kasus ini disejajarkan dengan Sri (Sadana) sebagai dewi padi (kemakmuran). Oleh karenaitu dalam tradisi pedalangan dijumpai Lakon Sri Mulih yang lazim dipentaskan sebagai lakon ruwatan dalam acara bersih desa. Gelar Darmaputra tampak sebagai usaha tradisi pedalangan untuk menonjolkan kapasitas Puntadewa sebagai putra Batara Darma, sebagai suami Dewi Sri (dewi penguasa pangan). Pemahaman ini tampak dipertegas dengan kedudukan Dewi Drupadi sebagai Permaisuri Puntadewa, bukan istri Pandawa seperti dalam Mahãbhãrata.

Gelar Darmawangsa diartikan karana dènira jumeneng nata manut rèh préntahing kadang dalam pengertian bahwa kedudukan Puntadewa sebagai raja bukanlah kehendaknya, tetapi atas kehendak saudaranya. Kata darmawangsa terbentuk dari kata darma dang wangsa. Darma (Sanskrit $=$ dharma) berarti pokok ajaran, kebajikan, kebenaran, kewajiban, tempat keramat, candi pemujaan atau pemakaman, saudara angkat atau segolongan (Mardiwarsita, 1990: 171-172). Wangsa dalam bahasa Jawa Kuna wangsa (Sanskrit = wamsa) yang berarti bangsa, kaum, keluarga, keturunan. Pengertian darmawangsa untuk gelar Puntadewa tersebut di atas diambil dari kata darma dalam arti kewajiban dan wangsa dalam arti saudara atau keluarga. Jadi jelas bahwa penggunaan gelar Darmawangsa untuk menegaskan bahwa Puntadewa menjadi raja Amarta hanya sekedar memenuhi kewajiban atas kehendak semua saudaranya. Hal demikian diperjelas dengan sikapnya bahwa meskipun Puntadewa telah menjadi raja, tetapi segala sesuatu yang berkaitan dengan kenegaraan diserahkan kepada keempat saudaranya, atau dengan kata lain bahwa 
kedudukan Puntadewa sebagai raja Amarta hanyalah sebagai simbol.

Makna darmawangsa lebih jauh dapat ditarik ke dalam pemahaman mistis. Kedudukan sebagai raja adalah idaman setiap orang tidak berlaku dalam pikiran Puntadewa. Keikhlasan yang berlebihan sehingga seolah-olah Puntadewa tidak memiliki sama sekali kemauan dan keinginan duniawi mengarah kepada pemahaman tentang kesempurnaan sifat brahmana (insan kamil). Dia hidup bukan karena makanan, dia terhormat bukan karena kedudukan. Yang bersemayam dalam sanubarinya hanyalah penyerahan diri kepada Yang Maha Kuasa. Dari keikhlasan dan penyerahan diri inilah yang menyebabkan ia satusatunya tokoh yang mampu mencapai nirwana beserta raganya atas tuntunan Batara Darma dalam bentuk anjing putih.

Satu hal yang menarik perhatian adalah apakah gelar Darmawangsa ini memiliki keterkaitan dengan raja Kediri Çri Dharmawangça Teguh Anantawikramotunggadewa? Dugaan ini beralasan karena pada masa pemerintahan Dharmawangsa, kitab Mahãbhãrata disadur dalam bahasa Jawa Kuna (Roekmono, 1973: 51). Pada sisi lain sangat mungkin kemunculan ini pada jaman Airlangga dalam rangka menjalin hubungan Dharmawangsa (Puntadewa) dengan Arjuna (Airlangga) dalam kitab Arjunawiwaha? Untuk membuktikannya perlu penelitian lebih lanjut.

Penonjolan Puntadewa sebagai identifikasi kebajikan dan kebenaran dipertegas lagi dengan gelar Gunatalikrama yang berarti pinter nalèni basa. Arti ini mengandung makna bahwa basa yang dimaksud bukan sekedar perkataan, tetapi lebih cenderung pada sikap penghormatan. Jadi Puntadewa adalah seorang yang sangat menghargai keberadaan antarsesamanya. Dalam hatinya selalu berprinsip jangan sampai menyakiti hati orang lain (karyènak tyasing sasama), selalu menghargai keberadaan seluruh makhluk berdasarkan kodratnya masing-masing (tan ngendhak gunaning jalma). Puntadewa seorang yang tidak pernah berbohong. Ia selalu mengatakan hal yang sebenarnya meskipun hal tersebut membahayakan dirinya atau bertolak belakang dengan kepentingan kelompoknya. Dengan demikian jelas bahwa makna dari gelar Puntadewa yang menyertakan kata darma merupakan gambaran dari sifat-sifatnya. Makna gelar tersebut memiliki kesejajaran dengan kapasitas Dewa sebagaimana makna puntadewa. Oleh karena itu tampak bahwa gelar Puntadewa merupakan identifikasi aspek Dewa Darma.

Karakter Puntadewa sebagai darmakusuma, darmaputra, dan gunatalikrama mendudukkannya sebagai orang yang tidak memiliki musuh sebagaimana gelarnya, yakni sang Ajathasatru. Gelar Ajathasatru dapat dimaknakan sebagai sifat yang selalu menganggap sebagai saudara atau teman kepada seluruh makhluk, terutama manusia. Puntadewa selalu mengasihi orang lain seperti halnya mengasihi dirinya sendiri bahkan melebihi. Karakter ini memiliki kesejajaran dengan makna Mitra dalam tradisi Mahãbhãrata. Mitra dianggap sebagai dewa kasih-sayang, dewa perdamaian (Macdonell, 1974: 30). Karakter Puntadewa sebagai Ajathasatru dapat disejajarkan dengan aspek Mitra. Dengan demikian dapat ditafsirkan bahwa penggunaan nama Ajathasatru merupakan identifikasi aspek Mitra dalam diri Puntadewa. Aspek Mitra ditransformasikan ke dalam diri Puntadewa untuk mempertegas atau menyempurnakan kebajikan Puntadewa sebagai putra dan sekaligus inkarnasi Batara Darma. Kebajikan Puntadewa dalam tradisi pedalangan digambarkan sangat sempurna, dan untuk menyangatkan, ia dipersonifikasikan sebagai orang yang darahnya berwarna putih. Warna putih ditafsirkan sebagai lambang kesucian sehingga dalam diri Puntadewa mengalir segala kesucian seperti halnya darah yang mengalir merata di seluruh tubuh.

\section{Gelar Yudistira sebagai Aspek Indra}

Adiparwa menunjukkan bahwa Puntadewa adalah inkarnasi Indra (Siman Widyatmanta, 1968: 89). Puntadewa merupakan salah satu dari panca indera Indra (Hiltebeitel, 1990: 98). Hal ini berkaitan dengan kedudukannya sebagai raja di Indraprasta (Amarta). Kata prasta (prastha) ada hubungannya dengan istilah prasthisthèng (dhampar kencana) dalam sulukan yang berarti duduk (menduduki/bertahta). Jadi Indraprastha artinya yang bertahta di Indraloka, merupakan identifikasi Indra.

Indra, dalam tradisi Mahãbhãrata disebutkan sebagai putra Aditi (Hopkins, 1986: 122). Sebagaimana nama indra yang berarti raja, ia adalah Surapati (raja para dewa). Seorang raja 
adalah manifestasi tipikal kesatria yang selalu mengayomi seluruh negeri dan rakyatnya dari berbagai ancaman. Ia sangat sakti dan mampu merubah wujudnya menjadi seorang raksasa yang sangat mengerikan (Macdonell, 1974: 38). Indra adalah penguasa alam semesta, penguasa airdan memberikannya kepada bumi agar padi dapat tumbuh dan berkembang (Hopkins, 1986: 128). Indra adalah penguasa kehidupan.

Hubungan antara Indra dan Yuddhishthira selain ditunjukkan bahwa Yuddhishthira sebagai inkarnasi Indra, juga ditunjukkan dalam penggunaan gelar Mahendra oleh Indra. Mahendra pada sisi lain digunakan sebagai nama busur Yuddhisthira (baca: Puntadewa) (Hopkins, 1986: 124). Makna kata yuddhishthira merupakan salah satu perwujudan dari aspek Indra, yakni sebagai penghancur musuh (kesatria) (Bhattacharjji, 1970: 258). Dalam tradisi Mahãbhãrata, Yuddhishthira ditunjukkan sebagai seorang prajurit. Ia berdiri sebagai senapati dalam Bhâratayuddha untuk menghancurkan musuh. Seorang prajurit dalam medan pertempuran hanya memiliki dua pilihan, dibunuh atau membunuh. Dalam kasus kematian Drona, sikap demikian tampak lebih jelas. Ketika Drona mendengar teriakan tentang kematian Ashvatthaman, ia mengira bahwa anaknya telah mencapai ajalnya. Untuk membuktikan kebenaran berita tersebut, Drona bertanya kepada orang yang tidak pernah berbohong, yakni Yuddhishthira. Mendapat pertanyaan Drona, Yuddhishthira membenarkan bahwa Ashvatthaman telah mati, tanpa menjelaskan bahwa Ashvatthaman yang mati adalah seekor gajah. Katz (1989: 160) memandang kebohongan Yuddhishthira merupakan konsekwensi kedudukannya sebagai prajurit dalam rangka mencapai kemenangan.

Penggunaan gelar Yudistira merupakan transformasi dalam menjaga kontinuitas kapasitas Indra dalam Puntadewa. Gelar Yudistira dalam pedalangan juga diartikan sebagai mustikaning prajurit. Makna ini tidak sesuai dengan karakter Puntadewa. Hal demikian menunjukkan bahwa transformasi Yuddhishthira dalam tradisi pedalangan mengalami diskontinu. Puntadewa seharusnya memiliki watak seorang prajurit dan pemimpin perang yang tangguh sebagaimana Yuddhishthira. Namun kenyataannya sifat Puntadewa dalam tradisi pedalangan justru sebaliknya. Jangankan membunuh, menyakitipun
Puntadewa tidak akan melakukannya. Ia seorang yang sangat jujur dan menghargai perkataan. Hal demikian ditunjukkan dalam kasus kematian Durna (kasus yang sama dengan identifikasi kapasitas prajurit Yuddhishthira dalam tradisi Mahäbhãrata). Kasus kematian Durna dalam tradisi pedalangan telah mengalami perubahan (diskontinu). Nama Ashvatthaman untuk putra Durna berubah menjadi Aswatama, dan gajah Ashvatthaman menjadi Hestitama. Ketika Durna bertanya kepada Puntadewa mengenai berita tentang kematian Aswatama, Puntadewa dengan jujur menjawab bahwa yang mati adalah "hestitama", tetapi ketika mengucapkan kata "hesti" volume suaranya pelan. Dengan demikian tampak bahwa dalam transformasinya mengalami kontinuitas, dan sekaligus terjadi diskontinu.

Perubahan nama Ashvatthaman menjadi Hestitama untuk mempertegas perbedaan antara nama gajah dan putra Durna. Dengan perbedaan nama akan mempermudah mengidentifikasikan dari si empunya nama. Penyebutan nama Ashvatthaman (gajah) oleh Yuddhishthira dan Hestitama oleh Yudistira merupakan usaha dalam menjada kuntinuitas narasi yang tanpa mengikutsertakan kata gajah. Dan kasus Yudistira dengan menyebutkan Hestitama sebenarnya untuk menunjuk bahwa yang mati adalah gajah dalam rangka menjaga kejujurannya. Tetapi karena penyebutan kata hesti dengan suara pelan, maka Durna yang pikirannya sedang kalut menangkap bahwa Aswatama benar-benar telah gugur di pertempuran. Lirihnya pengucapan hesti disebutkan atas pengaruh kekuatan Kresna. Dengan demikian jelas bahwa ketidaksesuaian antara karakter Puntadewa dengan makna nama Yudistira indikasi tentang pemilihan sebuah aspek yang ingin ditonjolkan dalam transformasi Puntadewa (Bandingkan dengan Kuntara, 1990: 463), yakni sisi kebajikan dan kejujurannya.

Kontinuitas transformasi Yuddhishthira dilakukan dengan cara menciptakan beberapa lakon wayang (sebagai proses diskontinu) yang dijalin dalam sebuah mata rantai. Fenomena yang memunculkan nama Yudistira terdapat dalam Lakon Babat Alas Mertani, yakni setelah Prabu Jim Yudistira menitis ke dalam diri Puntadewa. Hal demikian menunjukkan bahwa transformasi Yudistira tidak berlangsung serta merta, tetapi melalui tahapan-tahapan yang berkesinambungan 
dengan cara diciptakan beberapa lakon yang berkaitan dengan keberadaan Yudistira. Mata rantai transformasi Yudistira dapat dilacak melalui lakon-lakon sebagai berikut.

Lakon Wisnu Ratu yang dipentaskan Ki Hadi Sugito dalam rangka HUT Kedaulatan Rakyat ke 53 pada tanggal 28 September 1998 mengisahkan bahwa Wisnu turun ke dunia untuk membabat hutan Purwa Carita dan mendirikan negara Dwaraka. Bersamaan dengan berdirinya negara Dwaraka, serta berdiri pula negara Mertani (Indraprastha) sebagai imbangannya. Mengenai peristiwa di negara Mertani (Jejer VI) dikisahkan bahwa Prabu Jim Wilawuk (raja negara Mertami) ingin mengangkat putra sulungnya yaitu Jin Yudistira untuk menggantikannya sebagai raja. Jim Yudistira menyanggupi tetapi terlebih dahulu harus mendapatkan pusaka Kyai Jamus Kalimasada. Tiba-tiba diributkan oleh dua orang raksasa (Wisnu yang telah berubah wujud melawan Karungkala) berkelai. Prabu Wilawuk segera melindungi anak-anaknya dalam pelukan. Tindakan Wilawuk dicela Hyang Pada Wenang. Akibatnya Jim Wilawuk dikutuk menjadi seekor naga. Sebagai tebusannya, Jim Wilawuk harus bertapa di pertapaan Pring Cendani dan berganti nama Begawan Wilawuk. Ia dibekali minyak Jayengkaton dan Jalasutra. Atas petunjuk Sang Hyang Pada Wenang, Yudistira akhirnya mendapatkan pusaka Jamus Kalimasada, jelmaan Dewi Sadatwati, Dewi Kencanawulan, Raden Kalimakusuma, dan naga Candrasengkala. Sang Hyang Pada Wenang menyuruh Jim Ydistira untuk menjadi raja di Mertani dan berpesan bahwa pemegang pusaka Jamus tidak boleh melakukan angkara murka. Sebagai seorang Jim, Yudistira tetap memiliki watak raksasa, maka ketika pantangan itu dilanggar, seketika negara Mertani hilang dari pandangan mata tertutup oleh kekuatan gaib, yang tampak hanya hutan belantara. Negara Mertani akan muncul kembali apabila Pandawa membabat hutan Mertani.

Lakon Wisnu Ratu telah memunculkan nama Yudistira dan sekaligus telah disebutkan memiliki keterkaitan dengan para Pandawa di masa yang akan datang. Lakon ini merupakan indikasi sebagai mata rantai yang pertama dalam menjalin kisah-kisah transformasi Yudistira. Nama lain dari Mertani adalah Indraprasta (Indraprastha). Makna dari indraprastha dapat ditafsirkan sebagai kahyangan Sang Hyang Indra, sehingga penguasa di Mertani dapat diidentikkan dengan Dewa Indra. Disebutkan bahwa Yudistira adalah Jim yang tidak lepas dari sifat raksasa. Kapasitas Yudistira demikian dapat dipandang sebagai identifikasi aspek raksasa Dewa Indra (bandingkan dengan Macdonell, 1974: 38). Meskipun disebutkan bahwa Yudistira adalah pemilik Jamus Kalimasada tetapi tipikalnya belum memenuhi persyaratan sebagai pemegang Jamus Kalimasada, oleh karena itu untuk melengkapinya harus menunggu saatnya Pandawa membabat hutan Mertani.

Disebutkan pula dalam Lakon Wisnu Ratu bahwa terjadinya negara Dwaraka bersamaan dengan terjadinya negara Indraprasta. Indraprasta merupakan pasangannegaraDwaraka(Dwarawati). Pasangan ini merupakan personifikasi dari pasangan antara Indra (Indraprasta = Pandawa) dan Wisnu (Dwarawati = Kresna). Wisnu adalah adik sekaligus asisten Indra. Keduanya merupakan satu kesatuan yang tak terpisahkan (Gonda, 1969: 29). Sebagai saudara muda, Wisnu selalu mengikuti jejak Indra, sebagaimana ketika Indra berdiri sebagai Mahendra, Wisnu sebagai Upendra (Hopkins, 1986: 204). Demikian juga ketiga Indra menitis ke dunia menjelma menjadi lima Pandawa, Wisnu pun mengikutinya dengan menjelma menjadi Narayana dan Baladewa (Siman Widyatmanta, 1968: 89). Hal demikian pula yang menjadi dasar munculnya personifikasi hubungan antara Pandawa dan Kresna sebagai sesotya lan embanané (cincin dan matanya), kereta dan kusirnya. Keduanya merupakan satu kesatuan yang tidak dapat dipisahkan.

Lakon kedua adalah Lakon Babat Alas Mertani, mengisahkan keberhasilan Pandawa membabat hutan Mertani dan mendapatkan kerajaan Amarta. Dalam lakon ini dikisahkan pula terjadinya penitisan Jim Yudistira ke Raden Dwijakangka, Jim Dandun Wacana menitis kepada Raden Bratasena, Jim Dananjaya menitis ke Raden Permadi, Jim Nakula menitis ke Raden Pinten, dan Jim Sadewa menitis ke Raden Tansen. Kekalahan Jim Yudistira bukan karena kesaktian Dwijakangka, tetapi karena ciri-ciri yang dimilikinya. Dwijakangka secara terpaksa bersedia menghadapi Jim Yudistira, tetapi bukan untuk perang melainkan untuk menyerahkan diri. Ketika Jim Yudistira menggigit Dwijakangka, ia mengetahui bahwa Dwijakangka 
darahnya berwarna putih. Ciri-ciri demikianlah yang ditunggunya sebagai tempat penitisan untuk mencapai kesempurnaan. Jim Yudistira segera menitis ke Dwijakangka dan berpesan agar Dwijakangka menjadi raja di Amarta dan menggunakan gelar Prabu Yudistira.

Lakon Babat Alas Mertani merupakan kesinambungan dari Lakon Wisnu Ratu seperti yang telah disebutkan Sang Hyang Pada Wenang bahwa negara Amarta akan kembali ke sedia kala apabila Pandawa membuka hutan Mertani. Bentuk demikian merupakan usaha untuk menjaga jalinan mata rantai dari kisah Yudistira, hubungan antara Dwarawati jaman Kresna dengan Amarta pada jaman Puntadewa, dan bahkan mata rantai sistem transformasi Yudistira menjadi Puntadewa.

Pengertian raksasa dalam tradisi pedalangan telah menjadi satu kesatuan dengan pengertian buta, diyu, ditya, dan gandarwa (jim). Keberadaan Yudistira sebagai jim memiliki kesamaan makna dengan raksasa. Oleh karena itu dimunculkannya Jim Yudistira dalam tradisi pedalangan sebagai transformasi dari aspek raksasa Indra. Penggunaan gelar Yudistira bagi Puntadewa setelah Jim Yudistira menitis ke dalam diri Puntadewa. Nama Yudistira hanyalah nunggak semi. Dengan demikian wajar apabila makna yudistira tidak sesuai dengan sifat pokok Puntadewa karena nama tersebut hanyalah nama "titipan". Meskipun demikian pada saatsaat tertentu aspek Yudhistira sebagai raksasa akan muncul dalam diri Puntadewa.

Pada sisi lain keberadaan hutan Mertani sebagai kerajaan Jim merupakan pemunculan alam pemikiran Jawa dalam tradisi pedalangan. Dalam alam pikiran mistis Jawa diakui bahwa gunung, pohon besar, sungai dan sebagainya ada "penunggunya". Sang penunggu bisa menyatu hidup berdampingan dengan orang yang cocok bahkan menyatu atau menitis. Pandangan tentang penyatuan ini lebih jauh dapat ditarik ke dalam pemahaman tentang prewangan, yakni seseorang yang mampu mendatangkan atau kerasukan roh leluhur tertentu ke dalam dirinya. Kerasukan ini biasanya atas permintaan seseorang untuk menjalin komunikasi dengan arwah leluhur. Dengan demikian transformasi Yudistira menjadi Puntadewa dalam tradisi pedalangan merupakan proses kontinuitas konsep Yuddhishthira Mahãbhãrata, dan sekaligus untuk menyertakan alam pemiikiran Jawa.
Ketiga, Lakon Raden Narasoma. Lakon ini berkesinambungan dengan Lakon Salya Gugur. Permasalahan yang berkaitan dengan Puntadewa adalah kapasitasnya sebagai orang yang memiliki darah berwarna putih. Darah putih Puntadewa selain sebagai personifikasi sifat kebajikan yang sempurna seperti telah disebutkan di atas, pada sisi lain tampak sebagai usaha untuk menjalin rangkaian kisah gugurnya Salya oleh Puntadewa dalam Baratayuda dengan gugurnya Begawan Bagaspati oleh Raden Narasoma.

Begawan Bagaspati adalah seorang pertapa raksasa yang sangat sakti. Ia memiliki aji yang bernama Candrabirawa (ada pula yang menyebut Candhabirawa). Selain sangat sakti, sang begawan juga berbudi mulia dengan personifikasi darahnya berwarna putih. Ketika Raden Narasoma menjadi menantunya, Raden Narasoma merasa malu memiliki mertua seorang raksasa. Menghadapi persoalan demikian, Begawan Bagaspati dengan ikhlas menyerahkan hidupnya kepada Raden Narasoma dan memberikan aji Candrabirawa. Namun Begawan Bagaspati berpesan bahwa apabila Raden Narasoma berhadapan (sebagai musuh) dengan seseorang yang darahnya berwarna putih, maka aji Candrabirawa akan meninggalkannya dan menyatu dengan orang yang darahnya berwarna putih tersebut. Fenomena demikian menunjukkan adanya kesejajaran antara Bagaspati (raksasa) dan Yudistira (jim), namun dalam konteks yang berbeda. Peranan kedua tokoh tersebut akan menyatu dalam perang Baratayuda Jayabinangun ketika Puntadewa berhadapan dengan Salya.

Pesan Begawan Bagaspati kepada Salya terbukti dalam perang Baratayuda ketika Salya berhadapan dengan Puntadewa. Ketika Salya dengan kesaktian aji Candrabirawa memakan banyak korban dari pihak Pandawa, Kresna meminta kepada Puntadewa untuk menghadapi Salya. Puntadewa dengan perasaan segan terpaksa harus berhadapan dengan Salya. Ketika keduanya berhadapan, aji Candrabirawa melihat bahwa dalam diri Puntadewa terdapat Begawan Bagaspati sehingga Cadrabirawa meninggalkan Salya dan menyatu dalam diri Puntadewa. Hal demikian pula yang menyebabkan gugurnya Salya di medan Baratayuda, terkena pusaka Jamus Kalimasada. Dengan demikian jelas bahwa pesan begawan Bagaspati merupakan usaha untuk 
merangkai jalinan mata rantai kisah pedalangan dalam mendukung transformasi Puntadewa sebagai orang yang tidak mau berperang tetapi berhasil membunuh Salya dalam Baratayuda Jayabinangun. Dengan darahnya yang berwarna putih, Puntadewa berhasil meruwat dosa Salya tanpa harus melawannya dalam perang tanding. Berbagai sanggit kematian Salya ditampilkan dalang dalam mewujudkan karakter Puntadewa sebagai orang yang anti permusuhan.

Berdasarkan etimologi, hubungan Bagaspati dengan Narasoma memiliki kemiripan dengan Brehaspati dan Narãsamsa dalam mitologi Wedik. Brehaspati adalah tokoh dalam tataran mite yang menjadi pasangan Indra. Ia adalah seorang brahmana yang sangat sakti dan mejadi pemimpin para Brahmana. Kapasitas Brehaspati berdiri sebagai api (Agni), ia dipandang sama dengan Narãsamsa (bentuk lain dari Agni). Di dalam mite (pemujaan) Indra, Brehaspati didudukkan seperti halnya Agni, yakni digunakan sebagai sarana yang sangat ampuh dalam membebaskan perasaan dari rasa ketakutan. Di sini Brehaspati dikaitkan dengan sebuah ritual sebagaimana kapasitasnya sebagai Brahmana yang sangat sakti dan pemimpin para brahmana (Brahmanaspati) (Macdonell, 1974: 101-103). Brehaspati adalah pemimpin dalam korban kuda untuk pemujaan Indra (Hopkins, 1986: 130).

Transformasi Brehaspati menjadi Bagaspati, sedangkan Narãsamsa menjadi Narasoma. Kontinuitas transformasi Brehaspati ditunjukkan dengan cara mendudukkan Bagaspati sebagai Brahmana, serta Bagaspati memiliki istri bidadari. Transformasi kesaktian mengalami diskontinu dengan diwujudkan menjadi aji Candrabirawa, dan kesuciannya dipersonifikasikan dengan darahnya berwarna putih. Kesamaan kapasitas Brehaspati dengan Narãsamsa dalam pedalangan diwujudkan dengan menitisnya aji Candrabirawa ke dalam diri Narasoma. Namun pada saatnya nanti harus berpisah, dan Candhabirawa menyatu dengan orang yang darahnya berwarna putih. Kisah ini merupakan usaha untuk mempertahankan kesucaian Bagaspati.

Menitisnya jim Yudistira dan aji Candrabirawa pada Puntadewa merupakan kontinuitas kapasitas Brehaspati sebagai pasangan Indra. Kedua kapasitas ini sama-sama memiliki aspek raksasa. Dengan demikian dapat dikatakan bahwa kemampuan
Puntadewa untuk merubah wujudnya menjadi raksasa merupakan perwujudan hubungan antara Puntadewa dengan Bagaspati pada satu sisi, dan pada sisi lain sebagai manifestasi dari aspek raksasa Indra. Bagaspati sebagai transformasi dari Brehaspati untuk menjalin kontinuitas kedudukannya sebagai pasangan Indra. Pada saat kapasitas Indra berdiri sebagai pasubanda dalam korban kuda, Brehaspati adalah pemimpin dalam pemujaan Indra. Dengan demikian kemampuan Puntadewa untuk merubah wujudnya menjadi raksasa selain sebagai mata rantai dari kisah Begawan Bagaspati tetapi sekaligus sebagai bentuk kontinuitas dari sebagian tipikal Indra dalam diri Puntadewa; Dengan demikian digunakannya gelar Yudistira merupakan proses kontinuitas aspek Indra dalam proses transformasi Yuddhishthira menjadi Puntadewa oleh tradisi pedalangan. Dinobatkannya Raden Dwijakangka menjadi raja di Mertani yang disebut pula negara Amarta atau Indraprasta dengan gelar seperti yang disebutkan di atas mempertegas kapasitas aspek Indra sebagai surapati di dalam dirinya. Berdasarkan uraian di atas transformasi Yuddhisthira dalam tradisi pedalangan dapat digambarkan dalam diagram (gambar 1).

Dengan demikian tampak bahwa wayang sebagai mitologi Jawa merupakan sumber filsafat yang terefleksikan dalam karakter, nama (gelar), keberadaan (tempat tinggal), dan atributnya, yang diformulasikan menjadi lakon wayang. Setiap terjadinya perubahan mitologi, berarti terjadi perubahan filsafatnya, dan akibatnya terjadi pula perubahan lakon wayang. Demikian pula sebaliknya bahwa apabila terjadi perubahan dalam lakon wayang akan mengakibatkan terjadinya perubahan pada mitologi dan filsafatnya (Gambar 2).

\section{Penutup}

Berdasarkan uraian di atas tampak bahwa proses transformasi dalam wayang mengalami diskontinu dan sekaligus kontinu secara bersamaan. Hal demikian tampak pada transformasi Yuddhishthira menjadi Puntadewa dengan munculnya beberapa perbedaan karakter. Dalam kontinuitasnya tradisi pedalangan memilih karakter yang ingin ditonjolkan oleh masyarakat Jawa. Perbedaan karakter Puntadewa merupakan diskontinu sekaligus kontinuitas dari transformasi 


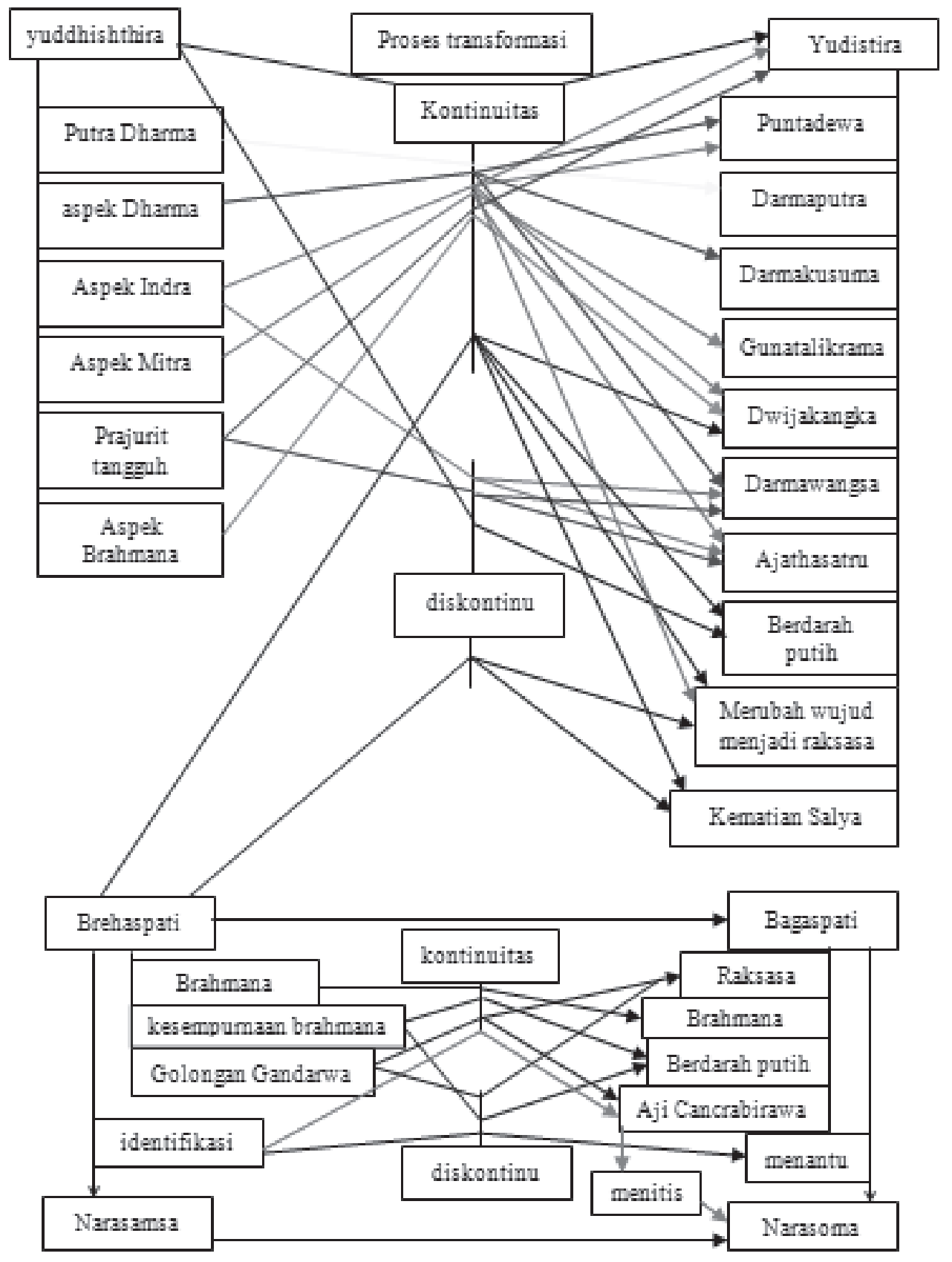

Gambar 1. Diagram proses diskontinu-kontinuitas transformasi dalam pedalangan (Wahyudi, 2012).

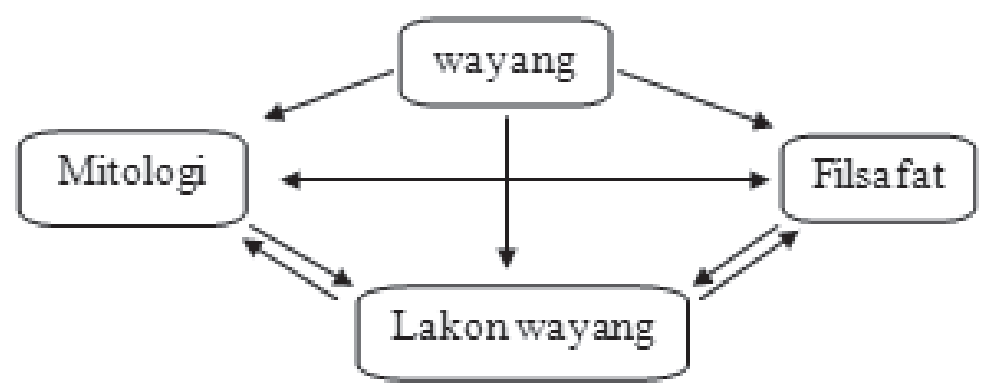

Gambar 2. Diagram hubungan makna dan fungsi wayang

(Wahyudi, 2012) 
Yuddhishthira untuk memilih karakter Puntadewa yang ingin ditonjolkan.

Kemunculan gelar-gelar Puntadewa tampak sebagai usaha untuk menonjolkan aspek Darma, dan Mitra dalam menjaga kontinuitas Yuddhishthira tradisi Mahãbhãrata. Gelar Puntadewa untuk menunjukkan dan menonjolkan idealisme masyarakat Jawa bahwa seorang raja merupakan manifestasi Illahi. Gelar Darmaputra untuk menunjukkan identifikasi Putadewa sebagai putra sekaligus inkarnasi Dewa Darma. Gelar Darmakusuma untuk menonjolkan kapasitas aspek darma sebagai sumber kebajikan dan kebenaran. Gelar Darmawangsa untuk menonjolkan sifat keikhlasan dan penyerahan diri kepada Yang Maha Kuasa sebagai kapasitas brahmana yang sempurna (insan kamil). Gelar Gunatalikrama merupukan penonjolan sifat menghargai sesama makhluk hidup sebagai perwujudan kapasitas aspek Mitra. Gelar Ajathasatru untuk menegaskan dan menyempurnakan kebajikan dari aspek Mitra dan Darma melalui darahnya yang berwarna putih.

Berdasarkan hal tersebut tampak bahwa aspek Indra (sebagai pemimpin prajurit) dalam Puntadewa ditekan sedemikian rupa agar tidak menonjol. Penekanan aspek Indra dilakukan secara kreatif melalui beberapa tahap dengan menciptakan lakon-lakon baru yang dijalin dalam sebuah mata rantai untuk membentuk satu kesatuan makna secara guna mempertahankan kontinuitas konsepnya. Kemunculan Lakon Wisnu Ratu dan Babat Alas Mertani merupakan media untuk menyatukan aspek Indra dalam diri Puntadewa, tetapi aspek Indra di sini dipahamkan hanya menempel melalui penitisan Jim Yudistira. Proses demikian dilakukan untuk menjaga keutuhan jalinan kisah (mulihing lakon) dalam lakon wayang agar ketika bermuara pada peristiwa perang besar di Kuruksetra lakon pedalangan dapat kembali pada induknya. Seperti yang ditunjukkan dalam lakon-lakon Baratayuda, semua tokoh rekaan baru dimatikan.

\section{Kepustakaan}

Ahimsa Putra, Heddy Shri. 1998. "Sebagai Teks dalam Konteks Seni dalam Kajian Antropologi
Budaya” SENI, Jurnal Pengetahuan dan Penciptaan Seni. Yogyakarta: PB ISI edisi Mei. 2001. Strukturalisme Lévi-Strauss: Mitos dan Karya Sastra. Yogyakarta: Galang Press

Aris Wahyudi. 2001. "Sanggit dan Makna Lakon Wahyu Cakraningrat Sajian Ki Hadi Sugito.” Tesis untuk mencapai derajad Sarjana S-2, Program Pascasarjana Universitas Gadjah Mada, Yogyakarta.

Bhattacharji, Sukumari. 1970. The Indian Theogony. Cambridge: At The University Press

Brandon, James R. 2003. Jejak-jejak Seni Pertunjukan di Asia Tenggara. Terjemahan R.M. Soedarsono. Bandung: P4ST UPI

Gonda, J. 1969. Ancient Indian Kingship From The Religious Point of View. Leiden: E.J. Brill

Hiltebeitel, Alf. 1990. The Ritual of Battle; Krishna in The Mahabharata, Albany: State University of New York Press

Hopkins, Edward Washburn. 1986. Epic Mythology. Delhi: Motilal Banarsidass.

Katz, Ruth Cecily. 1989. Arjuna In The Mahabharata: Where Krishna Is, There Is Victory US: University Of South Carolina Press.

Laksono, P. M.. 1985. Tradisi Dalam Struktur Masyarakat Jawa: Kerajaan dan Pedesaan. Yogyakarta: Gadjah Mada University Press

Macdonell, A.A. 1974. Vedic Mythology. Delhi: Motilal Banarsidass

Manu Jayaatmaja. 1994. "Pasubandha di Kuruksetra: Durgapuja menurut Lakon Baratayuda Tradisi Pedalangan Ngayogyakarta" dalam Pemasyarakatan Sastra Pewayangan. Yogyakarta: Jurusan Sastra Daerah Fakultas Sastra Universitas Gadjah Mada.

Mardiwarsito, L. 1990. Kamus Jawa Kuna Indonesia. Ende: Nusa Indah

Roekmono, R.. 1973. Pengantar Sejarah Kebudayaan Indonesia 2. Yogyakarta: Kanisius

Widyatmanta, Siman. 1968. Adiparwa: Djilid II. Jogjakarta: U.P. "Spring”.

Wignyosoetarno, Ki Ng. 1996. Wahyu Pakem Makutharama. Surakarta: STSI Press

Wiryamartana, I Kuntara. 1990. Arjunawiwaha. Yogyakarta: Duta Wacana University Press 